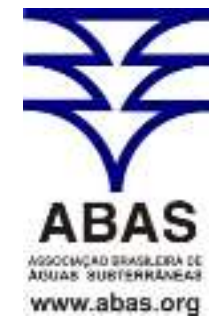

\section{QUANTIFICAÇÃO DA VULNERABILIDADE NATURAL À CONTAMINAÇÃO DAS ÁGUAS SUBTERRÂNEAS DA SUB-BACIA HIDROGRÁFICA JACARÉ-PEPIRA/SP}

\author{
QUANTIFICATION OF NATURAL VULNERABILITY TO GROUNDWATER \\ CONTAMINATION FROM HYDROGRAPHIC SUB-BASIN \\ JACARÉ-PEPIRA/SP
}

Artigo recebido em: 03/12/2015 e aceito para publicação em: 22/08/2016.

DOI: http://dx.doi.org/10.14295/ras.v30i3.28507

\begin{abstract}
Resumo: As águas subterrâneas representam aproximadamente $98 \%$ da água doce disponível e adequada ao consumo humano. Não obstante este seja um recurso de difícil acesso e relativa proteção natural, diversas atividades antrópicas apresentam potencial de contaminação de aquíferos suscetíveis. A vulnerabilidade das águas subterrâneas é uma propriedade intrínseca do meio físico e representa a facilidade ou dificuldade de um contaminante hipotético migrar verticalmente da superfície do terreno ao aquífero. O objetivo deste trabalho foi aplicar o método DRASTIC para quantificação da vulnerabilidade intrínseca das águas subterrâneas armazenadas nos aquíferos livres presentes na Sub-Bacia Hidrográfica Jacaré-Pepira (componente da UGHRI-13). Para o método DRASTIC Padrão foi encontrada vulnerabilidade 48,96\% Moderada, 44,14\% Baixa e 6,90\% Alta (não ocorrendo Vulnerabilidade Muito Alta). Para DRASTIC Pesticidas, obteve-se vulnerabilidade 53,54\% Moderada, 37,27\% Alta, 4,72\% Muito Alta e 4,47\% Baixa. Considerando-se os custos e tempo necessários para remediação de aquíferos, propõese a utilização do mapeamento da vulnerabilidade intrínseca do meio físico em avaliações preliminares frente a instalação de novos empreendimentos.
\end{abstract}

Palavras-chave: Vulnerabilidade. Águas subterrâneas. Aquíferos. DRASTIC. Contaminação.

Abstract: Groundwater represents approximately 98\% of available fresh water suitable for human consumption. Although this is a hard access resource and relative natural protection, there are several human activities with potential to contamination of susceptible aquifers. The vulnerability of groundwater is an intrinsic property of the physical environment and is the ease or difficulty of a hypothetical contaminant to vertically migrate from the ground surface to the aquifer. The objective of this study was apply the DRASTIC method to quantify the groundwater intrinsic vulnerability in unconfined aquifers from Hydrographic Sub-Basin Jacaré-Pepira (component of the UGHRI-13). For the Standard DRASTIC method was found vulnerability $48.96 \%$ Moderate, $44.14 \%$ and 6.90\% Low High (not occurring Vulnerability Very High). For DRASTIC Pesticides, was found vulnerability 53.54\% Moderate, 37.27\% High 4.72\% Very High and Low 4.47\%. Considering the costs and time required for aquifers remediation, it's proposed the use of intrinsic vulnerability mapping of the physical environment on preliminary evaluations against the installation of new enterprises.

Keywords: Vulnerability. Groundwater. Aquifers. DRASTIC. Contamination.

\section{INTRODUÇÃO}

A importância da água está relacionada aos seus diversos usos, como consumo, lazer, geração de energia e transporte (MA-
RENGO, 2008, SHRESTHA, 2016). A água no planeta Terra ocupa dois terços de sua superfície, sendo aproximadamente $98 \%$ deste volume água salgada (CETESB, 2014a). De toda água doce, excluindo-se as águas conge-

1 Universidade Federal de São Paulo (UNIFESP). Departamento de Ciências Ambientais, Instituto de Ciências Ambientais, Químicas e Farmacêuticas da UNIFESP. Área: Modelagem hidrogeológica . Email: douglas.tanajura@gmail.com

2 Universidade Federal de São Paulo (UNIFESP). Departamento de Ciências Ambientais, Instituto de Ciências Ambientais, Químicas e Farmacêuticas da UNIFESP. Área: Modelagem Hidrogeológica, Geologia, Modelagem Hidrogeoquímica, Geoestatística. E-mail: cbbleite@gmail.com 
ladas nos polos, somente $0,6 \%$ está tecnicamente disponível para uso humano, ou seja, pode ser aproveitada utilizando-se a atual tecnologia disponível. Do total de água doce e disponível, cerca de $2 \%$ é água superficial (rios e lagos) e $98 \%$ é água subterrânea (aquíferos) (MARENGO, 2008; CETESB, 2014a).

Em estudos recentes, a CETESB (2014a) identificou aumento gradativo e significativo no uso de águas subterrâneas no Brasil a partir de 1970. Para o Estado de São Paulo, em 2014, constatou-se que mais de 5,5 milhões de habitantes, em cerda de $80 \%$ de seus municípios, são abastecidos por água proveniente de fontes subterrâneas (CHRISTOFIDIS, 2003; CETESB, 2014a).

Diante deste cenário, as águas subterrâneas, por se tratarem de um recurso de alta qualidade natural, que exige pouco tratamento sanitário e com baixo custo de captação (CETESB, 2014b), se consolidam como uma alternativa estratégica para suprir a atual demanda de abastecimento humano (SHRESTHA et al., 2016). Assim, a crescente demanda urbana, a extração e o uso em larga escala de água subterrânea ao longo dos anos resultaram em forte pressão antrópica no mundo todo, entretanto, ainda são ausentes ou ineficientes os programas e políticas públicas efetivas para sua proteção frente aos impactos ambientais de subprodutos contaminantes advindos de diversas atividades (ALMEIDA, 2010, FIJANI et al., 2013, MIRANDA et al., 2015, SANTOS et al., 2015).

O evento de contaminação pode deflagrar-se tanto a partir de fontes difusas, que ocupam áreas extensas, como de uma fonte pontual, que ocupa pontos específicos, infiltrando-se verticalmente em direção à zona saturada do aquífero (MACHADO, 2002; SPERLING, 2005; ALBUQUERQUE FILHO et al., 2012). As atividades antrópicas são as principais causas de contaminação das águas subterrâneas, por exemplo: tanques de armazenamento subterrâneo em postos de combustíveis constituem fontes tradicionalmente pontuais, enquanto a agricultura é uma típica fonte difusa de contaminação (HIRATA, 1994; TUCCI et al., 2000; LIMA, 2001; LIBOS, 2002).
No Estado de São Paulo, notadamente na região da Bacia Hidrográfica Tietê-Jacaré, existem grandes áreas dedicadas ao agronegócio, por meio de atividades agroindustriais e agropecuárias. Nestas áreas, os agroquímicos são amplamente utilizados visando aumentar a produtividade, melhorar a fertilidade do solo e eliminar pragas e doenças nas plantações (FERRARO et al., 2015). Não obstante ao seu uso em larga escala, estudos indicam que apenas $0,1 \%$ de todo agroquímico utilizado atinge os organismos de interesse enquanto $99,9 \%$ migram para o meio natural, sendo os recursos hídricos (águas superficiais e subterrâneas) o seu principal destino final (YOUNOS e WEIGMANN, 1988).

Considerando os diversos fatores envolvidos na determinação da vulnerabilidade de aquíferos, deve-se considerar as características do meio físico e da contaminação em relação aos altos custos requeridos para remediação, as dificuldades operacionais e o tempo necessário para que sejam obtidos resultados satisfatórios (ALBUQUERQUE FILHO et al., 2012). A vulnerabilidade das águas subterrâneas é uma propriedade intrínseca do meio físico e representa a facilidade ou dificuldade de um contaminante migrar da superfície do terreno até a zona saturada de um aquífero, portanto, a vulnerabilidade reflete a fragilidade do sistema aquífero receber cargas contaminantes advindas de atividades antrópicas (pontuais ou difusas) em superfície (VRBA e ZAPOROZEC, 1994, MENEZES et al., 2013, MUHAMMAD et al., 2014).

Estudos científicos recentes têm demonstrado que trabalhos preventivos são ferramentas eficientes para proteção dos recursos naturais e, portanto, das águas subterrâneas (HIRATA, 1994; ERTEL et al., 2012). Diante deste desafio, incentivar o mapeamento e identificação das diferentes fragilidades do meio frente à contaminação dos recursos hídricos mostra-se uma importante fonte de subsídio técnico-científico na gestão e conservação destes recursos (LAGO et al., 2012; FIJANI et al., 2013; MENEZES et al., 2013; COELHO et al., 2013).

Assim, considerando a intensificação de atividades potencialmente degradantes da 
qualidade natural de águas subterrâneas no Estado de São Paulo e a necessidade desafiadora de execução de estudos com viés preventivo, definiu-se como objetivo desse trabalho a quantificação e mapeamento regional da vulnerabilidade das águas subterrâneas na Sub-Bacia Hidrográfica Jacaré-Pepira utilizando-se do método DRASTIC (ALLER et. al., 1985, 1987).

\section{CARACTERIZAÇÃO DA ÁREA DE ESTUDO}

A Sub-Bacia Jacaré-Pepira localiza-se na região central do Estado de São Paulo (Figuras 1 e 2) e possui área total de $2462,7 \mathrm{~km}^{2}$ com perímetro aproximado de $312,2 \mathrm{~km}$. O clima na região, de acordo com a classificação de Köppen (1948), é do tipo Cwa tropical de altitude com período de chuvas entre outubro e março, seco entre abril e setembro, com precipitação média anual de $1258 \mathrm{~mm}$, e temperatura média anual de $22^{\circ} \mathrm{C}$ (OLIVEIRA, 2004; TUNDISI et al., 2008, LEITE et al., 2013).

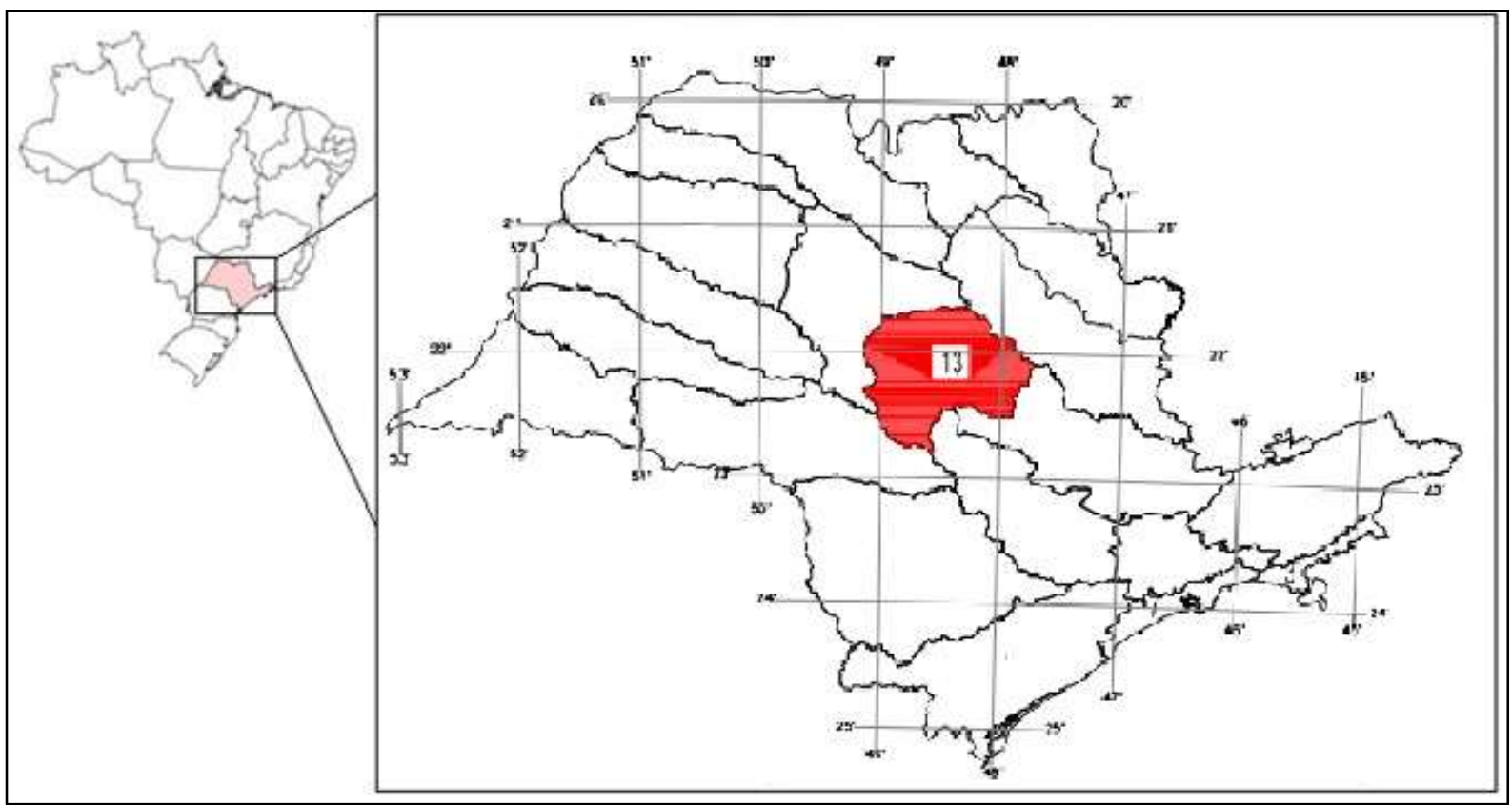

Figura 1 - Localização da UGRHI 13 no Estado de São Paulo

Figure 1 - Localization from UGRHI 13 in the São Paulo State 


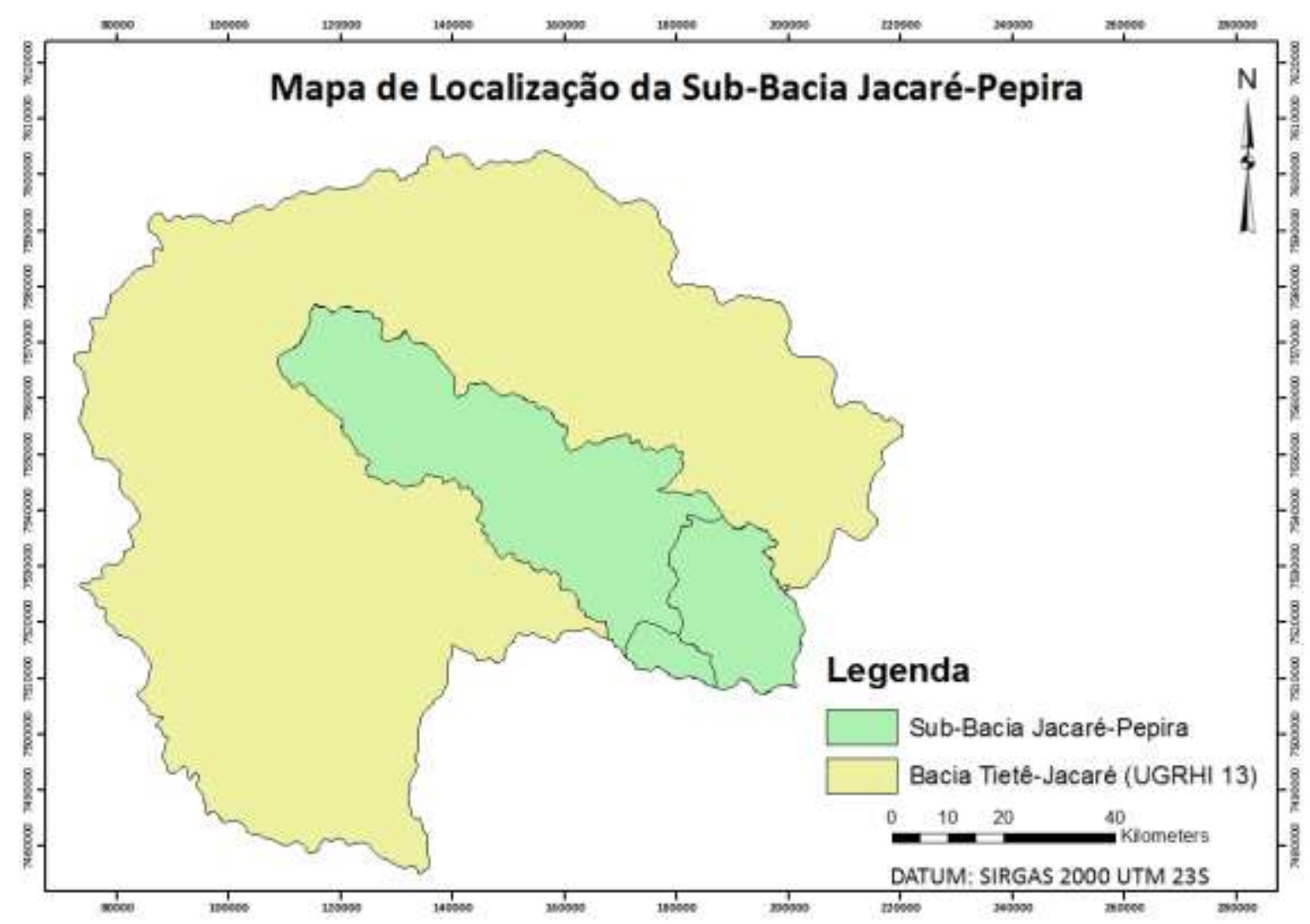

Figura 2 - Mapa de Localização da Sub-Bacia Jacaré-Pepira

Picture 2 - Localization Map from Hydrographic Watershed Jacaré-Pepira

A Geologia da Sub-Bacia Jacaré-Pepira (Figura 3), é constituída por litologias pertences ao Grupo São Bento, Grupo Bauru, Formação Itaqueri e Depósitos Aluvionares. Pertencentes ao Grupo São Bento, estão presentes rochas ígneas basálticas da Formação Serra Geral, arenitos eólicos da Formação Botucatu e arenitos eólicos e fluviais da Formação Piramboia. Pertencente ao Grupo Bauru, tem-se arenitos e lamitos fluviais da Formação Adamantina; ocorrem também arenitos conglomeráticos da Formação Itaqueri e, finalmente, Depósitos Aluvionares de origem fluvial (IPT, 1981).

Os solos encontrados na Sub-Bacia Jacaré-Pepira podem ser subdivididos em: Argissolos Vermelho-Amarelos: solos minerais com predominância textural de argila; Latossolos Vermelhos e Vermelho-Amarelos: solos minerais bastante espessos, ricos em ferro e textura predominantemente argilosa; Neossolos Quartzarênicos: constituídos texturalmente por areias, pouco desenvolvidos e pouco espessos; Neossolos Litólicos: solos pouco evoluídos, constituídos por fragmentos de rochas, pouco espessos e pouco desenvolvidos; Nitossolos Vermelhos: solos minerais com mais de $35 \%$ de argila em sua composição textural derivada de sua origem Basáltica; e Gleissolos que são solos minerais formados em condições de saturação de água tipicamente encontradas nas várzeas dos rios (SIBICS, 2006). 


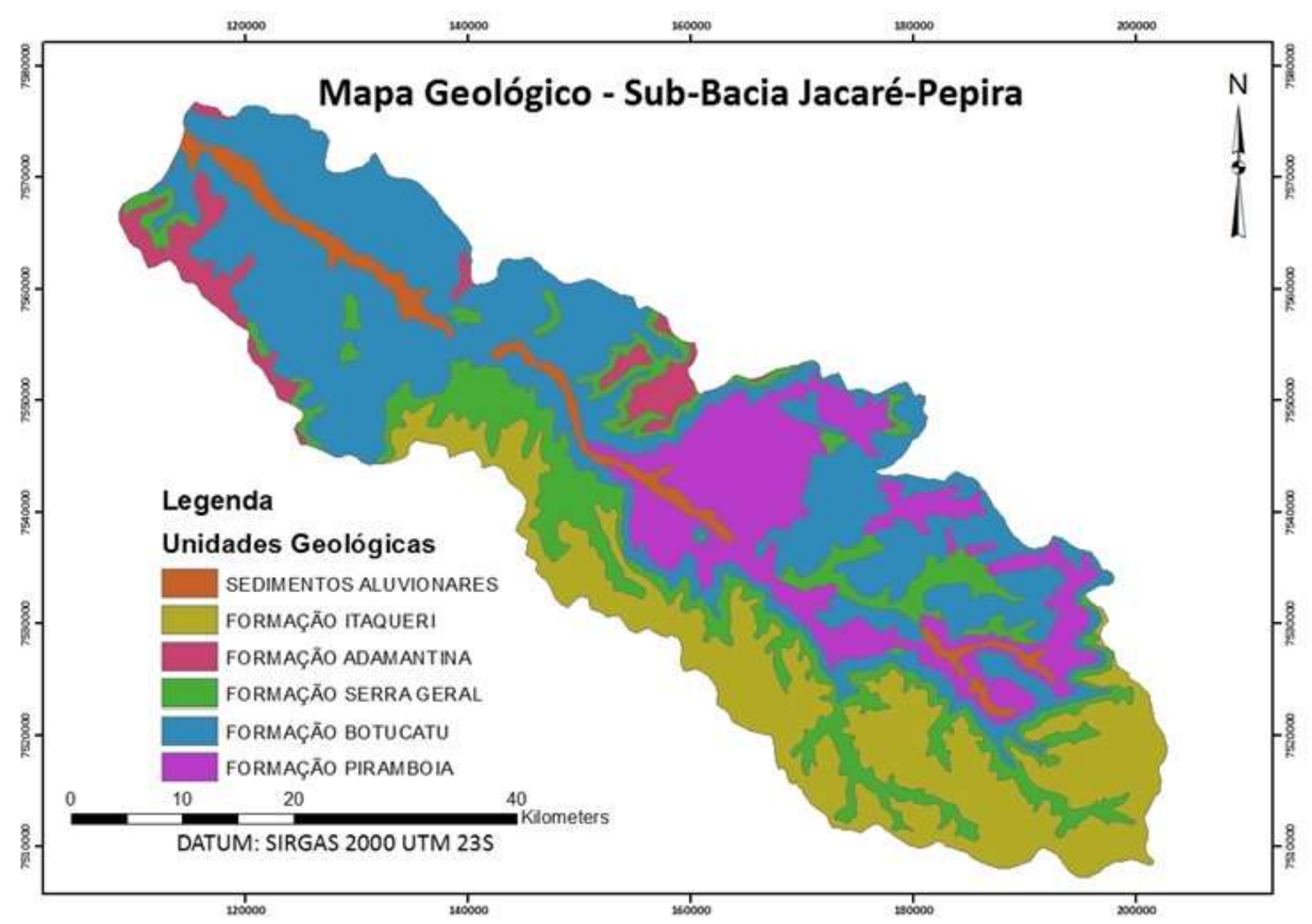

Figura 3 - Mapa Geológico da Sub-Bacia Jacaré-Pepira Figure 3 - Geologic Map from Hydrographic Watershed Jacaré-Pepira

\section{O MÉTODO DRASTIC}

A quantificação da vulnerabilidade intrínseca das águas subterrâneas foi realizada a partir da aplicação do método DRASTIC (ALLER et al. 1985, 1987). O acrônimo DRASTIC faz referência aos parâmetros considerados por Aller et al. (1985, 1987) (Figura 4):

- $\mathbf{D}=$ Depth to water (Profundidade do nível d'água);

- $\quad \mathbf{R}$ - net Recharge (Recarga do Aquífero);

- A - Aquifer media (Material do Aquífero);

- $\quad \mathbf{S}$ - Soil media (Tipo de Solo);

- T - Topography (Topografia);

- I - Impact of Vadose Zone media (Influência da Zona Vadosa);

- $\mathbf{C}$ - Hydraulic Conductivity of the aquifer (Condutividade Hidráulica do Aquífero).
Neste trabalho, foram aplicadas as duas derivações do método DRASTIC descritas por Aller et al. (1985,1987), como segue:

1) DRASTIC Padrão: considera que o contaminante tem a mesma mobilidade da água, simulando a introdução de contaminantes de mobilidade moderada no meio físico.

2) DRASTIC Pesticidas: considera que o contaminante tem a mesma mobilidade de um pesticida típico, simulando a introdução de contaminantes de alta mobilidade.

Ambas as derivações do método DRASTIC (Padrão e Pesticidas) obedecem quatro premissas básicas:

- A introdução do contaminante é realizada na superfície da área avaliada;

- O transporte do contaminante ocorre no sentido vertical até o nível d'água;

- A mobilidade considerada para o contaminante é a mesma da água; e 
- A área mínima para aplicação do método é de $0,4 \mathrm{~km}^{2}$.

Sendo assim, a vulnerabilidade é quantificada a partir da associação entre todos os parâmetros representados no acrônimo DR-A-S-T-I-C, considerando suas influências na dinâmica de movimentação do contaminante no meio físico. Com isso, considera-se o peso de cada parâmetro na obtenção do valor de vulnerabilidade proposto pelo método (Tabela 1) e o índice de cada classe dos parâmetros DRASTIC.

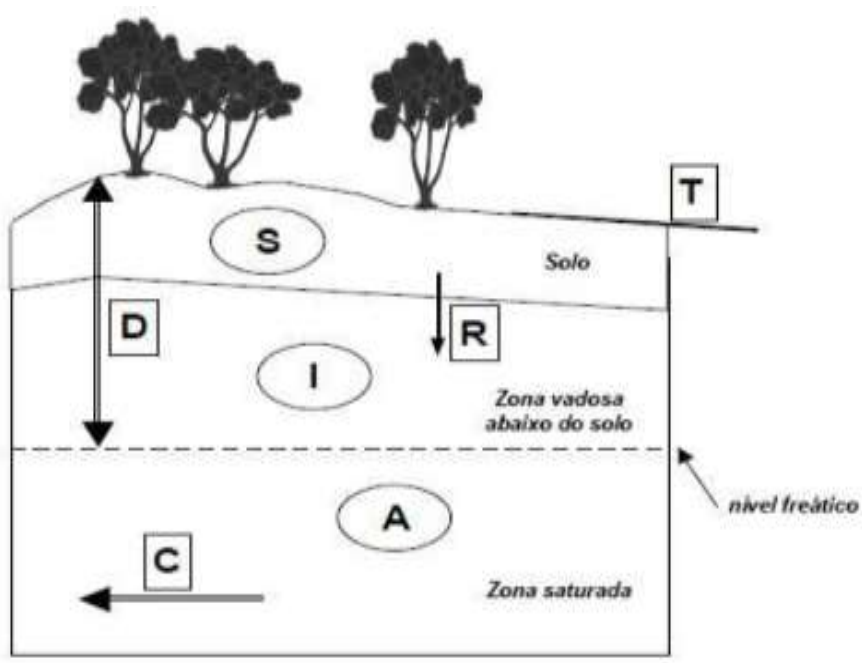

Figura 4 - Representação esquemática dos parâmetros do método DRASTIC

Figure 4 - Schematic representation of the DRASTIC method parameters

Tabela 1 - Valores dos pesos dos parâmetros DRASTIC

Table 1 - DRASTIC parameters weights values

\begin{tabular}{cccccccc}
\hline & $\mathrm{D}$ & $\mathrm{R}$ & $\mathrm{A}$ & $\mathrm{S}$ & $\mathrm{T}$ & $\mathrm{I}$ & $\mathrm{C}$ \\
\cline { 2 - 8 } Padrão & 5 & 4 & 3 & 2 & 1 & 5 & 3 \\
Pesticidas & 5 & 4 & 3 & 5 & 3 & 4 & 2 \\
\hline
\end{tabular}

Fonte: LEITE (2011)

Após obtenção dos pesos e os índices de cada parâmetro, aplica-se a somatória ponderada DRASTIC (Figura 5). Após estes cálculos, considerando-se que os parâmetros têm pesos diferentes pré-determinados (ALLER, 1985,1987), tem-se que a vulnerabilidade obtida pelo procedimento DRASTIC Padrão pode variar entre 23 (pouco vulnerável) e 226 (muito vulnerável), enquanto que para o procedimento DRASTIC Pesticidas a variação está entre 29 (pouco vulnerável) e 256 (muito vulnerável) (ALLER et al., 1985, 1987).
Para os dois procedimentos, a vulnerabilidade é classificada em:

- Vulnerabilidade Baixa - valores DRASTIC menores que 120

- Vulnerabilidade Moderada - valores DRASTIC entre 120 e 159

- Vulnerabilidade Alta - valores DRASTIC entre 159 e 199

- Vulnerabilidade Muito Alta - valores DRASTIC maiores que 199 


$$
D R A S T I C=D_{p} x D_{i}+R_{p} x R_{i}+A_{p} x A_{i}+S_{p} x S_{i}+T_{p} x T_{i}+I_{p} x I_{i}+C_{p} x C_{i}
$$

Figura 5 - Somatória ponderada para obtenção da vulnerabilidade DRASTIC

Figure 5 - Weighted Summation to obtain the DRASTIC vulnerability

\section{DESCRIÇÃO E OBTENÇÃO DOS PA- RÂMETROS DO MÉTODO DRASTIC}

Abaixo são apresentados os parâmetros DRASTIC (ALLER et al., 1985, 1987) e as operações realizadas na obtenção de cada parâmetro em ambiente SIG, a partir da utilização do Software ArcGIS® 10.1.

\section{D - Profundidade do nível d'água}

A profundidade do nível d'água (Tabela 2) representa a distância que o contaminante inserido na superfície terrestre terá que percorrer até atingir o lençol freático do aquífero. Para aquíferos livres esta distância corresponde à profundidade do nível de água subterrânea, entretanto, para aquíferos confinados a distância é medida do topo do aquífero até o nível de água subterrânea (LOBO FERREIRA, 1998; LNEC, 2002; LEITE et al., 2013).

Tabela 2 - Valores dos índices para o Parâmetro D

Table 2 - Index Values for D Parameter

\begin{tabular}{cccccccc}
\hline Profundidade (m) & $<1,5$ & $1,5-4,6$ & $4,6-9,1$ & $9,1-15,2$ & $15,2-22,9$ & $22,9-30,5$ & $>30,5$ \\
\hline Índice & 10 & 9 & 7 & 5 & 3 & 2 & 1 \\
\hline
\end{tabular}

Fonte: ALLER et al. $(1985 ; 1987)$

Seu mapeamento foi precedido pela construção de um Modelo Digital do Terreno (MDT) a partir de dados referentes à topografia, hidrografia e pontos cotados da área obtidos junto ao IBGE (Instituto Brasileiro de Geografia e Estatística). Em seguida, para obtenção do Modelo Digital de Potenciometria (MTP), foram interpoladas as cotas representadas pelos cruzamentos das linhas topográficas (cotas do terreno) com as linhas de drenagem e cota de nível d'água de poço obtidos junto ao IPT/SP (Instituto de Pesquisas Tecnológicas de São Paulo). Por fim, realizou-se a subtração de MDT pelo MTP, onde obtevese o mapa de profundidade do nível d'água na área de estudo (Figura 6).

\section{R - Recarga do aquífero}

A Recarga (Tabela 3) corresponde ao volume de água por área que se infiltra a partir da superfície do terreno e, portanto, tem o potencial de transportar contaminantes ao aquífero por fluxo vertical (HIRATA, 1994, JESUS, 2012). A quantidade de água infiltrada deriva da soma de processos como infiltração de água pluvial e fluvial, de modo que a migração de água à zona saturada sub-superficial influencia diretamente o fluxo de águas subterrâneas (LOBO-FERREIRA, 2000). 


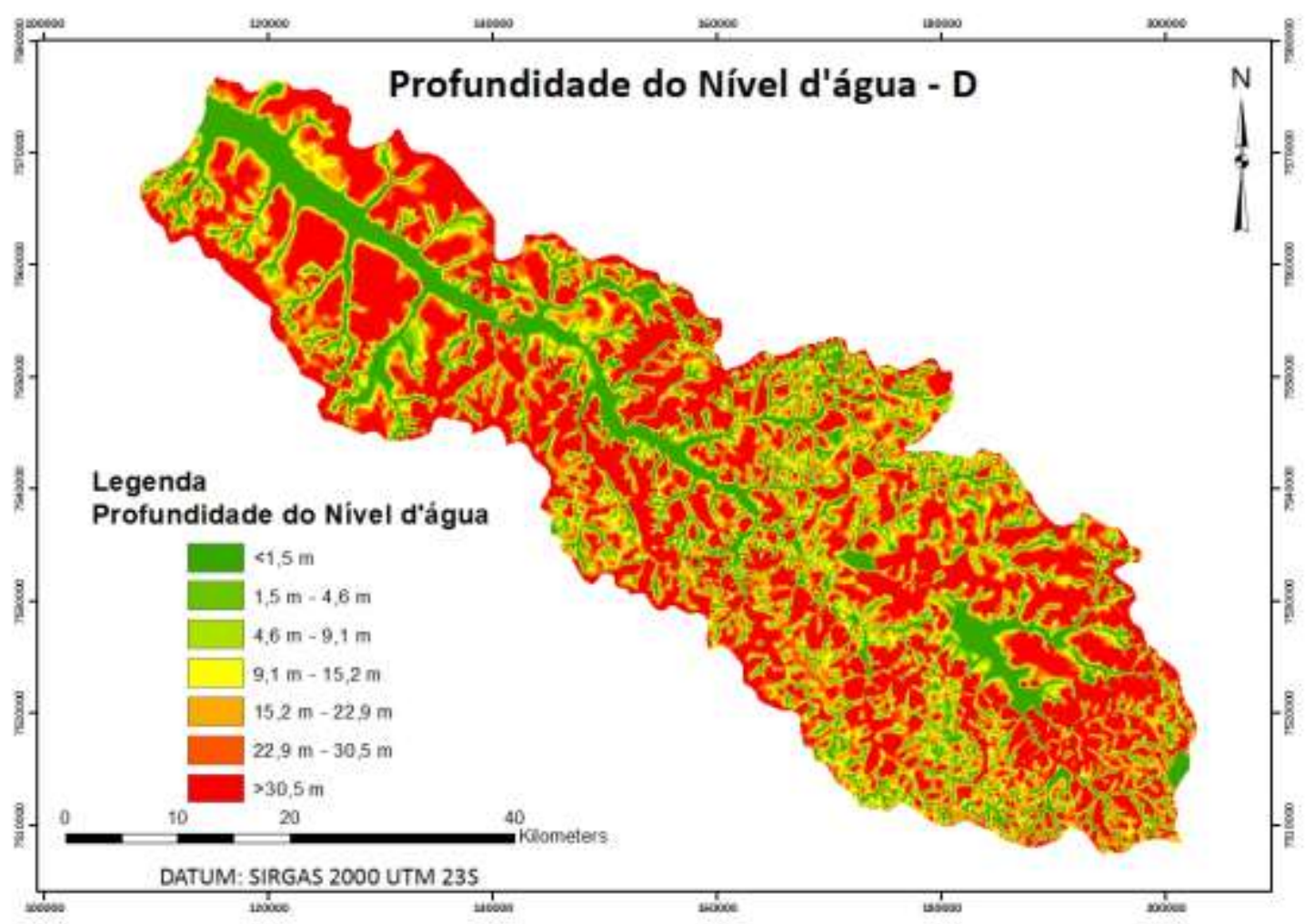

Figura 6 - Mapa de Profundidade do Nível d'água na Sub-Bacia Jacaré-Pepira Figure 6 - Water Depth Map from Hydrographic Watershed Jacaré-Pepira

Tabela 1 - Valores dos índices para o Parâmetro R Table 3 - Index Values for R Parameter

\begin{tabular}{cccccc}
\hline Recarga $(\mathbf{m m} / \mathbf{a n o})$ & $<51$ & $51-102$ & $102-178$ & $178-254$ & $>254$ \\
\hline Índice & 1 & 3 & 6 & 8 & 9
\end{tabular}

Fonte: ALLER et al. $(1985 ; 1987)$

Os dados de recarga mapeados (Fi- amento superficial realizada pelo método $D e$ gura 7) na área de estudo foram obtidos a par- $\quad$ chidr (Tabela 4) (OLIVEIRA, 2004; LEITE $e t$ tir da decomposição de hidrogramas de esco- $\quad$ al., 2013) 


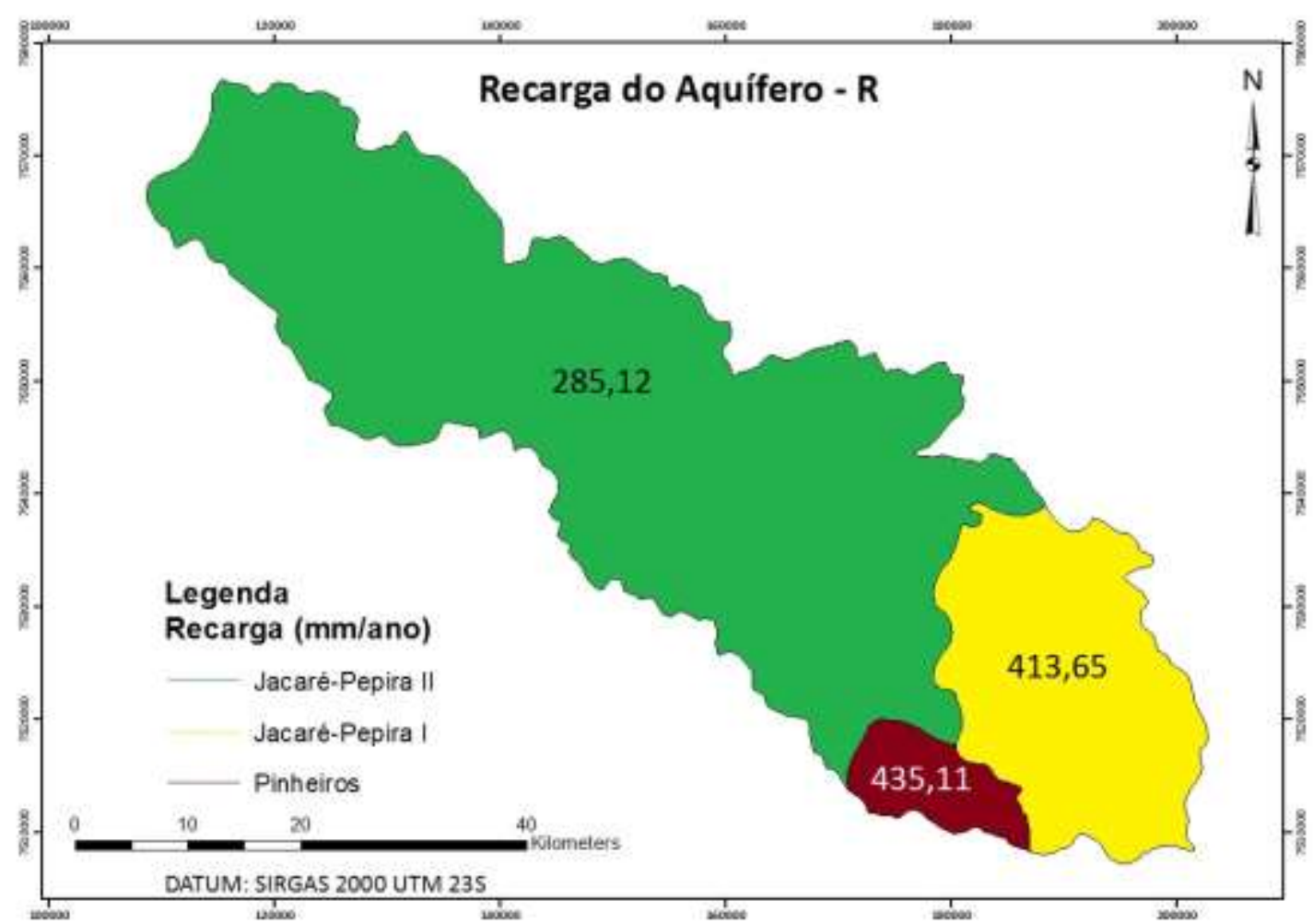

Figura 7 - Mapa de Recarga na Sub-Bacia Jacaré-Pepira

Figure 7 - Recharge Map from Hydrographic Watershed Jacaré-Pepira

Tabela 4 - Dados Hidrológicos obtidos a partir do método Dechidr

Table 4 - Hydrological data obtained from Dechidr method

\begin{tabular}{ccccc}
\hline & Precipitação & $\begin{array}{c}\text { Escoamento } \\
\text { Total }\end{array}$ & $\begin{array}{c}\text { Esc. Super- } \\
\text { ficial }\end{array}$ & $\begin{array}{c}\text { Esc. Subter- } \\
\text { râneo }\end{array}$ \\
\cline { 2 - 5 } Jacaré-Pepira I & 1180,79 & 505,19 & 91,54 & 413,65 \\
Jacaré-Pepira II & 1438,96 & 313,03 & 27,86 & 285,12 \\
Pinheiros & 1152,80 & 518,54 & 83,44 & 435,11 \\
Médias & $\mathbf{1 2 5 7 , 5 2}$ & $\mathbf{4 4 5 , 5 9}$ & $\mathbf{6 7 , 6 1}$ & $\mathbf{3 7 7 , 9 8}$ \\
\hline
\end{tabular}

Fonte: (OLIVEIRA, 2004; LEITE, 2013)

\section{A - Material do Aquífero}

O Aquífero é definido como uma unidade geológica com capacidade de armazenamento e produção de quantidades significativas de água subterrânea para abastecimento humano (LEITE et al., 2011). O material constituinte do Aquífero possui características morfo-granulométricas e distribuição espacial convergentes com sua natureza geológica (Tabela 5) que influenciam o transporte de contaminantes no meio saturado. Seu mapeamento foi originado a partir da síntese geológica da área de estudo, onde a interpretação da geologia local resultou na distribuição espacial do material de origem dos aquíferos e sua caracterização (Figura 8). 
Tabela 5 - Valores dos índices para o Parâmetro A

Table 5 - Index Values for A Parameter

\begin{tabular}{cc}
\hline Natureza do Aquífero & Índice (Índice típico) \\
\hline Xisto argiloso & $1-3(2)$ \\
Rocha metamórfica/ígnea & $2-5(3)$ \\
Rocha metamórfica/ígnea alterada & $3-5(4)$ \\
"Till" glaciar & $4-6(5)$ \\
Arenito, calcário e argilito estratificados & $5-9(6)$ \\
Arenito maciço & $4-9(6)$ \\
Calcário maciço & $4-9(6)$ \\
Areia e balastro & $4-9(8)$ \\
Basalto & $2-10(9)$ \\
Calcário carsificado & $9-10(10)$ \\
\hline
\end{tabular}

Fonte: ALLER et al. $(1985 ; 1987)$

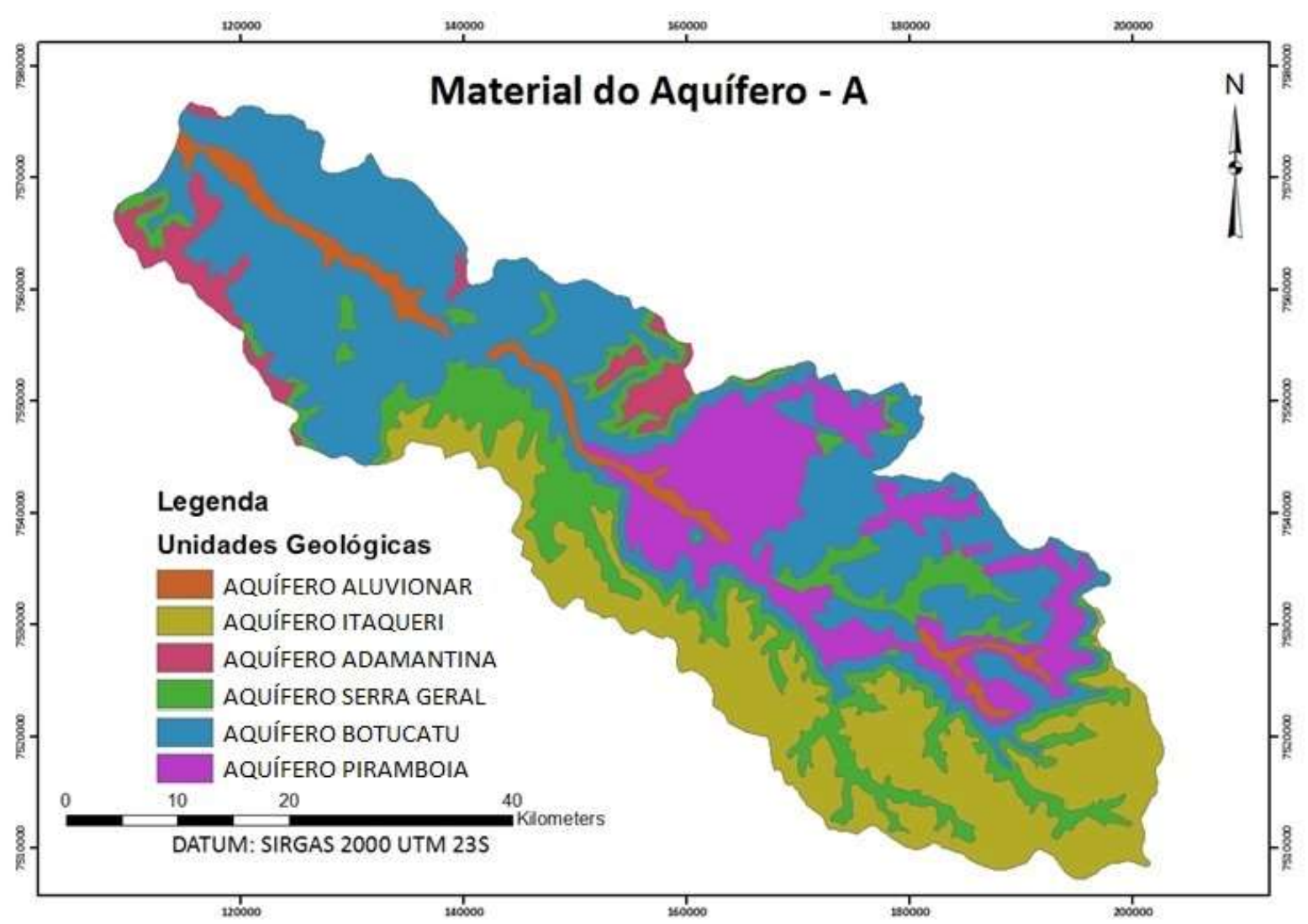

Figura 8 - Mapa do Material do Aquífero na Sub-Bacia Jacaré-Pepira

Figure 8 - Aquifer Media Map from Hydrographic Watershed Jacaré-Pepira

\section{S - Tipo de Solo}

O Solo tem características que condicionam a interação hidrodinâmica entre um contaminante e o solo durante o processo de migração contaminante da superfície do terreno ao nível de água subterrânea (LNEC, 2002). Aller et al. $(1985,1987)$ definiram as 4 principais características do solo relacionadas à vulnerabilidade: a) Espessura; b) Textura; c) Expansibilidade; d) Teor de matéria orgânica e os índices de vulnerabilidade para as categorias (tipos) de solo (Tabela 6).

Seu mapeamento (Figura 9) foi possível a partir da operação de vetorização em ambiente SIG das informações presentes no 
levantamento pedológico semi-detalhado do quisa Agropecuária) nas quadrículas Jaú, BroIAC (Instituto Agronômico de Campinas) e da tas e São Carlos (PRADO et. al., 1981). EMBRAPA (Empresa Brasileira de Pes-

Tabela 6 - Valores dos índices para o Parâmetro S

Table 6 - Index Values for S Parameter

\begin{tabular}{cc}
\hline Tipo de Solo & Índice \\
\hline Fino ou ausente & 10 \\
Balastro & 10 \\
Areia & 9 \\
Turfa & 8 \\
Argila expansível & 7 \\
Franco arenoso & 6 \\
Franco & 5 \\
Franco siltoso & 4 \\
Franco argiloso & 3 \\
"Muck" & 2 \\
Argila não-expansível & 1 \\
\hline
\end{tabular}

Fonte: ALLER et al. $(1985 ; 1987)$

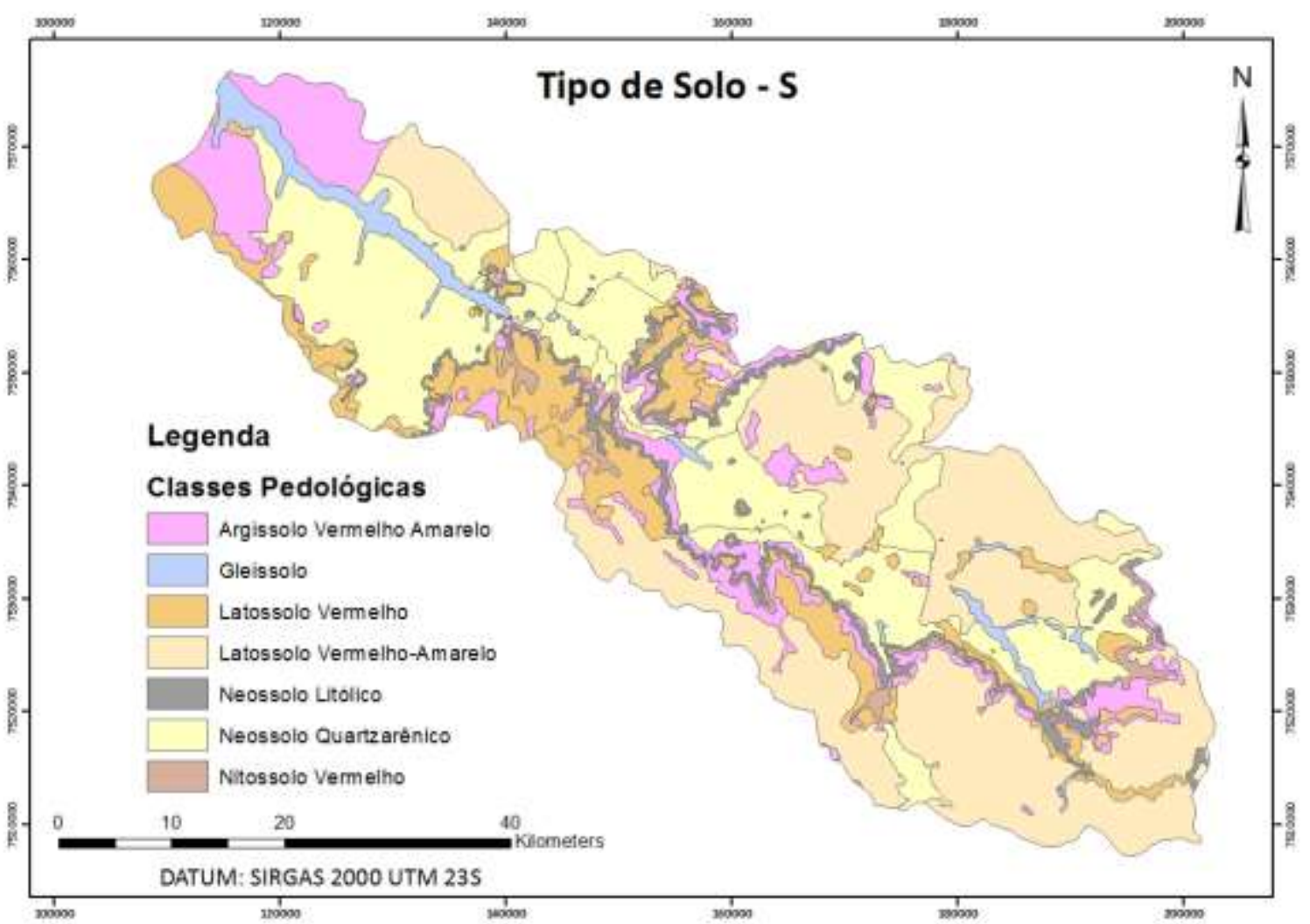

Figura 9 - Mapa Pedológico da água na Sub-Bacia Jacaré-Pepira

Figure 9 - Pedologic Map from Hydrographic Watershed Jacaré-Pepira 


\section{T - Topografia}

O parâmetro Topografia refere-se à variação da declividade no terreno da área em estudo (Tabela 7). Em geral, maiores declives proporcionam maior velocidade com predominância de escoamento superficial, enquanto menores declives favorecem a infiltração de água e contaminantes. Seu mapeamento foi executado em dois procedimentos em ambiente SIG.
No primeiro momento, o Modelo Digital do Terreno foi obtido a partir da interpolação dos dados obtidos junto ao IBGE referentes à topografia, hidrografia e pontos cotados na escala 1:50.000. Em seguida, foi obtida a variação da declividade do terreno, em porcentagem (\%), em toda área de estudo (Figura $10)$.

Tabela 7 - Valores dos índices para o Parâmetro T

Table 7 - Index Values for T Parameter

\begin{tabular}{cc}
\hline Topografia $($ declive em \%) & $\begin{array}{c}\text { Ín- } \\
\text { dice }\end{array}$ \\
\hline$<2$ & 10 \\
$2-6$ & 9 \\
$6-12$ & 5 \\
$12-18$ & 3 \\
$>18$ & 1 \\
\hline
\end{tabular}

Fonte: ALLER et al. $(1985 ; 1987)$

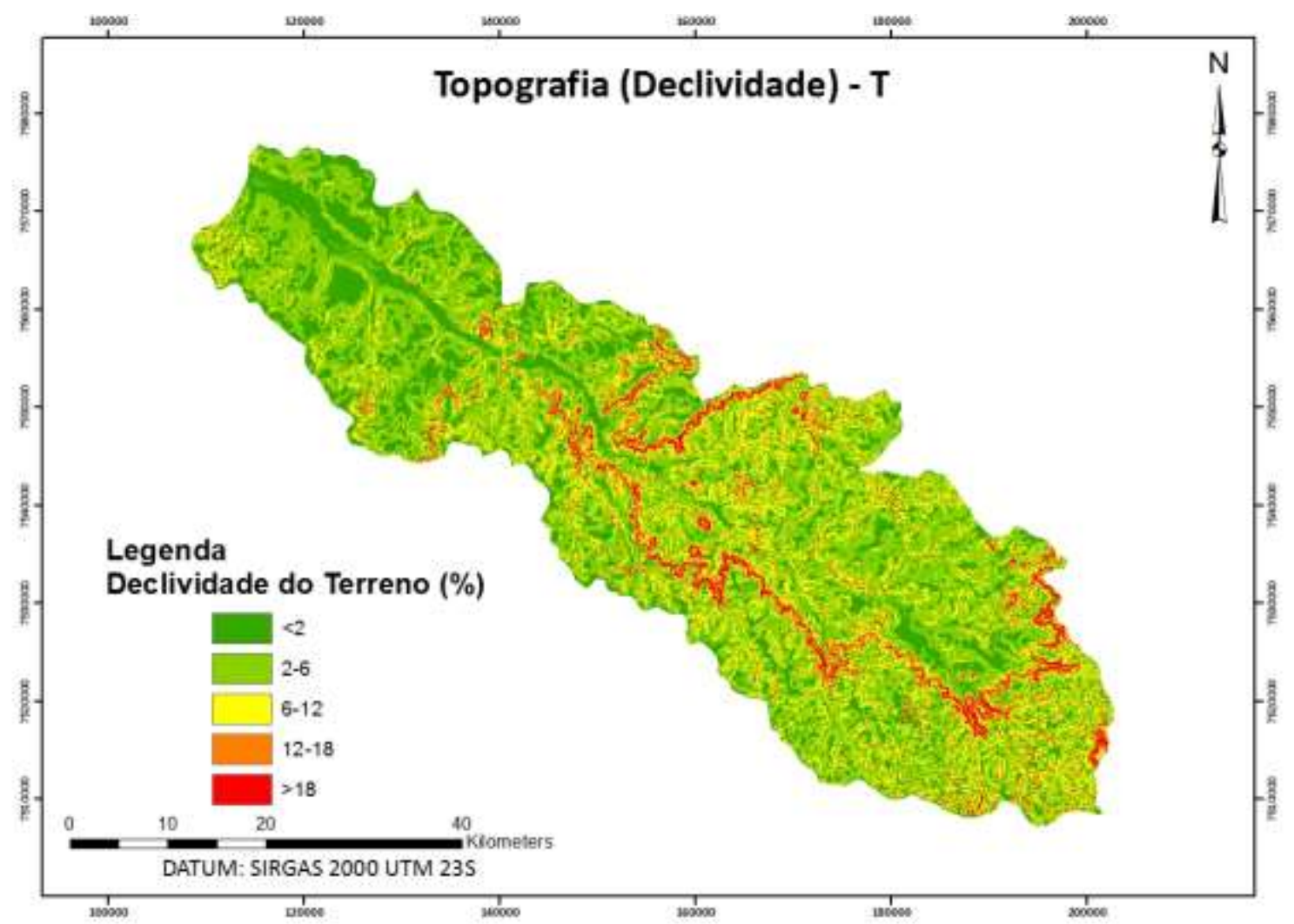

Figura 10 - Mapa Topográfico da água na Sub-Bacia Jacaré-Pepira

Figure 10 - Topographic Map from Hydrographic Watershed Jacaré-Pepira 


\section{I - Impacto da Zona Vadosa}

O parâmetro Impacto da Zona Vadosa pode ser definido como a caracterização da zona não-saturada entre o solo (abaixo do parâmetro S - Solo) e o nível de água subterrânea (MCGUFF e MCMULLEN, 2004). Sua distribuição espacial acompanha o arranjo espacial das unidades geológicas de origem e suas características hidrogeoquímicas determinam o tempo de migração até que o contaminante alcance o lençol freático (LNEC, 2002). Seu mapeamento (Figura 11) foi realizado em consonância com a síntese geológica da área de estudo (IPT, 1981) e o método DRASTIC (Tabela 8) (Aller et al., 1985, 1987).

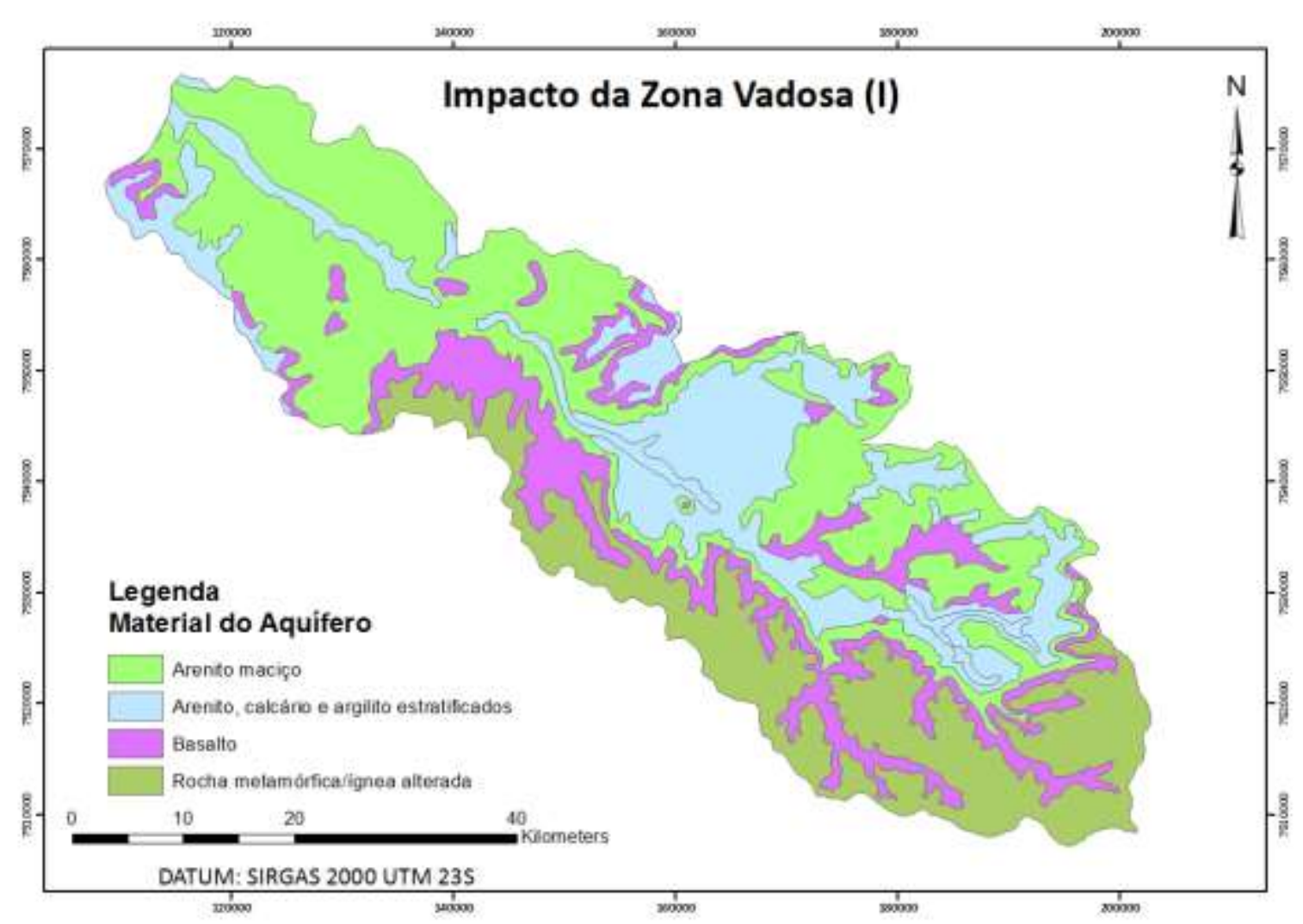

Figura 11 - Mapa do Impacto da Zona Vadosa na Sub-Bacia Jacaré-Pepira

Figure 11 - Vadose Zone Impact Map from Hydrographic Watershed Jacaré-Pepira

Tabela 8 - Valores dos índices para o Parâmetro I

Table 8 - Index Values for I Parameter

\begin{tabular}{cc}
\hline Influência da Zona Vadosa & Índice \\
\hline Camada confinante & 1 \\
Argila/Silte & $2-6(3)$ \\
Xisto argiloso, argilito & $2-5(3)$ \\
Calcário & $2-7(6)$ \\
Arenito & $4-8(6)$ \\
Arenito, calcário e argilito estratificados & $4-8(6)$ \\
Areia e balastro com percentagem significativa de silte e argila & $4-8(6)$ \\
Rocha metamórfica/Ígnea & $2-8(4)$ \\
Areia e balastro & $6-9(8)$ \\
Basalto & $2-10(9)$ \\
Calcário carsificado & $8-10(10)$ \\
\hline
\end{tabular}

Fonte: ALLER et al. $(1985 ; 1987)$ 


\section{C - Condutividade Hidráulica do Aquí-} fero

A Condutividade Hidráulica do Aquífero (Tabela 9) representa a facilidade na circulação da água no interior do aquífero. Os valores utilizados neste trabalho foram obtidos a partir da ponderação de informações disponíveis na literatura (IPT, 1981, SÃO
PAULO, 1990; CPRM, 2010), confrontandoas com a distribuição das litologias locais.

Como se observa na Figura 12, apenas um intervalo de condutividade foi definido, pois todas as unidades geológicas presentes apresentaram valores inferiores a 4,1m/dia (Figura 12).

Tabela 9 -Valores dos índices para o Parâmetro C

Table 9 - Index Values for C Parameter

\begin{tabular}{cc}
\hline Condutividade Hidráulica $(\mathbf{m} / \mathbf{d})$ & $\begin{array}{c}\text { Ín- } \\
\text { dice }\end{array}$ \\
\hline$<4,1$ & 1 \\
$4,1-12,2$ & 2 \\
$12,2-28,5$ & 4 \\
$28,5-40,7$ & 6 \\
$40,7-81,5$ & 8 \\
$>81,5$ & 10 \\
\hline
\end{tabular}

Fonte: ALLER et al. (1985; 1987)

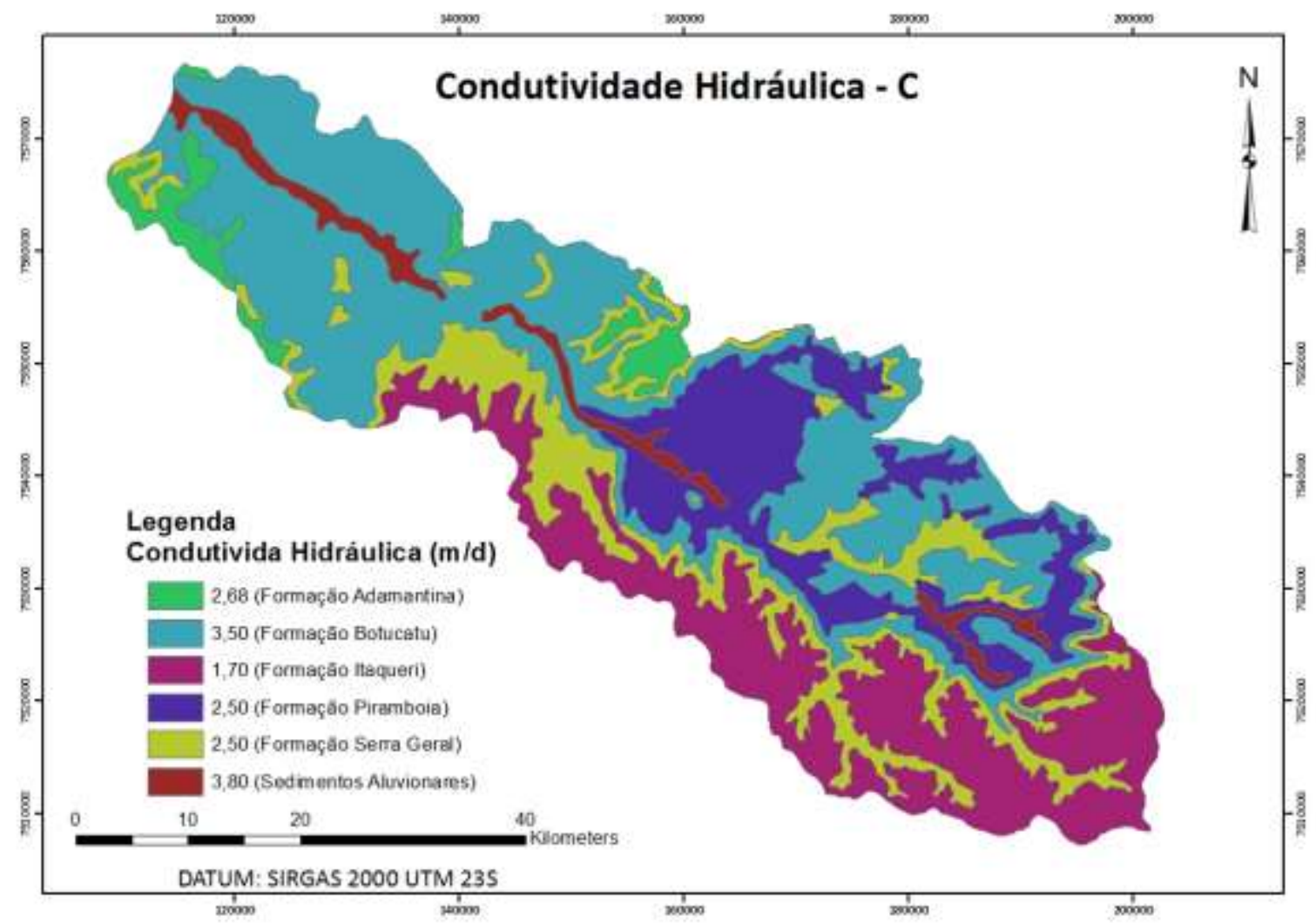

Figura 12 - Mapa de Condutividade Hidráulica na Sub-Bacia Jacaré-Pepira

Figure 12 - Hydraulic Conductivity Map from Hydrographic Watershed Jacaré-Pepira 


\section{RESULTADOS E DISCUSSÃO}

Os valores obtidos para DRASTIC Padrão (Figura 13) variaram entre 81 (Vulnerabilidade Baixa) e 189 (Vulnerabilidade Alta), com predominância de Vulnerabilidade Mo- derada $(48,96 \%)$ e Vulnerabilidade Baixa $(44,14 \%)$, totalizando $93,1 \%$ da área total. Complementarmente tem-se uma área de 6,90\% referente à Vulnerabilidade Alta, não se observando áreas com Vulnerabilidade Muito alta.

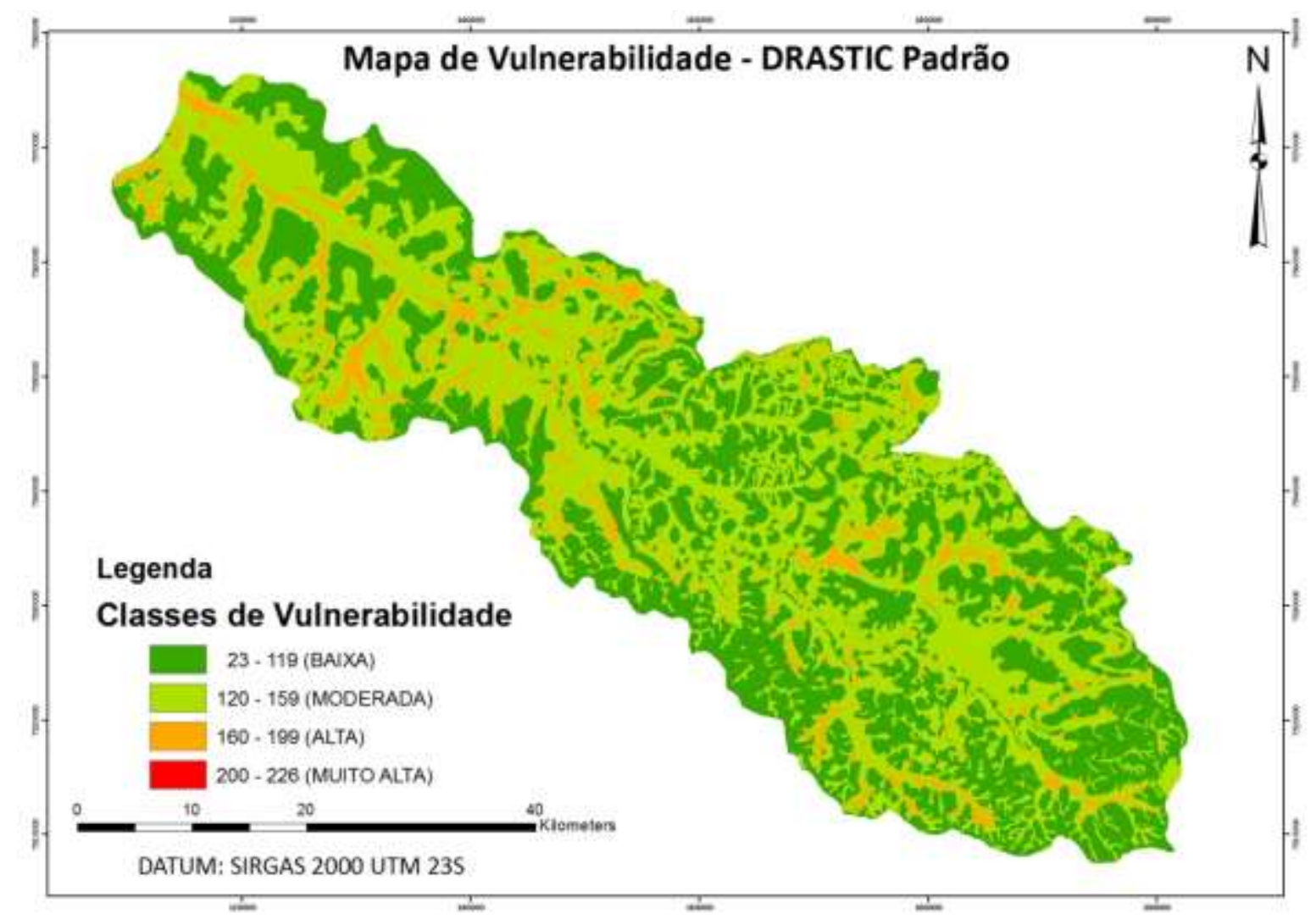

Figura 13 - Mapa de Vulnerabilidade da Sub-Bacia Jacaré-Pepira - DRASTIC Padrão Figure 13 - Vulnerability Map from Sub-Watershed Jacaré-Pepira/SP - Standard DRASTIC

À jusante, em direção a foz do rio Jacaré-Pepira, estão agrupadas as ocorrências de Vulnerabilidade Moderada e a maior porcentagem de Vulnerabilidade Alta de toda área, caracterizando o perímetro mais suscetível à contaminação. À montante predominam Vulnerabilidades Baixa e Moderada, com algumas concentrações isoladas de Vulnerabilidade Alta, mas em menor proporção em relação à região de jusante.
Para DRASTIC Pesticidas (Figura 14) os valores obtidos tiveram uma variação entre 81 (Vulnerabilidade Baixa) e 226 (Vulnerabilidade Muito Alta), com predomínio de Vulnerabilidade Moderada (53,55\%) e Vulnerabilidade Alta (37,27\%), equivalentes a 90,81\% da área total. Devido a diferenças conceituais, DRASTIC Pesticidas resultou nas classes de Vulnerabilidade Baixa $(4,47 \%)$ e Vulnerabilidade Muito Alta (4,72\%). 


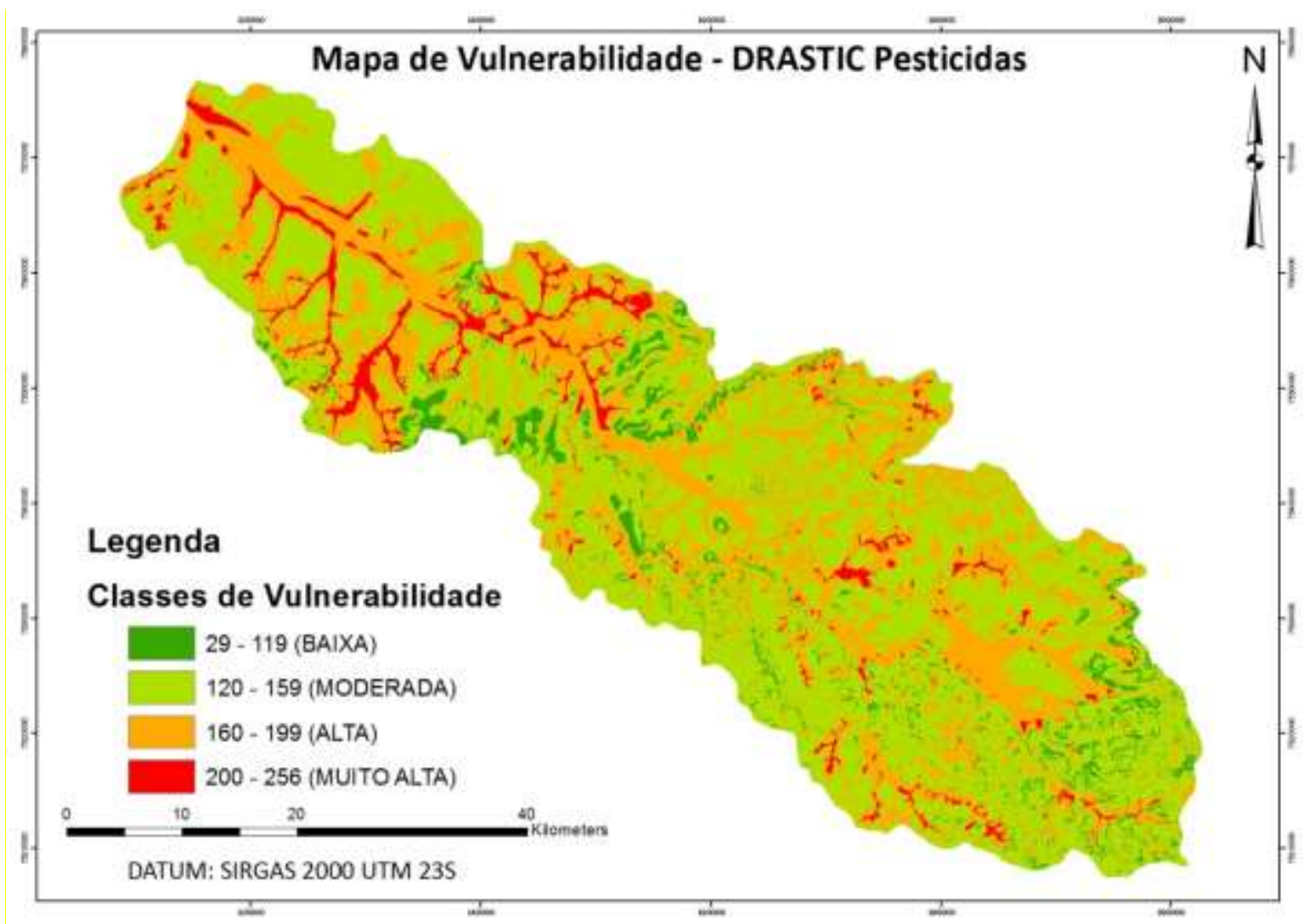

Figura 14 - Mapa de Vulnerabilidade daa Sub-Bacia Jacaré-Pepira - DRASTIC Pesticidas

Figure 14 - Vulnerability Map from Sub-Watershed Jacaré-Pepira/SP - Pesticides DRASTIC

Na porção jusante da área de estudo há predominância de Vulnerabilidade Moderada e Vulnerabilidade Alta com destaque à maior proporção de Vulnerabilidade Muito Alta de toda área. À montante, ocorre predominantemente Vulnerabilidade Moderada e Alta, com presença de Vulnerabilidade Alta em proporção consideravelmente inferior a região jusante.

$\mathrm{Na}$ área de estudo, a profundidade do nível de água subterrânea é maior nas zonas de interflúvios e menor quando se aproxima do corpo d'água superficial (rio). A profundidade do nível d'água tem relação diretamente proporcional ao tempo de migração de um potencial contaminante no trajeto entre a superfície do terreno e o lençol freático. Em regiões de menores profundidades há maior vulnerabilidade, dado o tempo de migração do contaminante da superfície ao lençol freático é pequeno e, portanto, há pouco retardamento por processos naturais atenuantes.

Desse modo, a instalação de atividades potencialmente poluidoras em áreas próximas aos corpos d'água representa alto risco à qualidade dos recursos hídricos subterrâneos. Deve-se então considerar a vulnerabilidade local na determinação do Uso e Ocupação do solo dando preferência à utilização de áreas afastadas o quanto for possível dos cursos d'águas superficiais. Esta deve ser uma ação padrão em políticas públicas futuras de zoneamento na área de estudo, mas pode ser generalizada para outras regiões com características semelhantes.

A vulnerabilidade também é fortemente influenciada pelo parâmetro Recarga. Quanto maior for a recarga, maiores volumes de água se infiltram pela superfície do terreno, com potencial de transportar contaminantes em fluxo vertical por toda a zona vadosa em direção à água subterrânea. Na Sub-Bacia Jacaré-Pepira há ocorrência de altas taxas de Recarga (mm/ano) e predominância de formações aquíferas areníticas, basálticas fraturadas e solos quartzarênicos (quantidades relativa- 
mente altas de areia em suas composições e alta permeabilidade).

Esta associação de parâmetros resulta em condições bastante favoráveis à contaminação, pois o grande volume de água infiltrado tem grande potencial de migração pelos espaços vazios interconectados (poros) até a zona saturada do aquífero. Associadas a estas configurações, a constituição arenosa dos aquíferos na área de estudo, caracterizada por materiais pouco porosos e muito permeáveis, permitem rápido deslocamento do contaminante e desfavorecem a atuação de processos atenuantes naturais, como adsorção, reações bioquímicas e dispersão que, por conseguinte, não favorecem processos de atenuação natural, (MCGUFF e MCMULLEN, 2004; LEITE, 2011).

Em relação à topografia, a Sub-Bacia Jacaré-Pepira apresenta uma pequena parcela de declives suavizados $(<2 \%)$ à montante no Rio Jacaré-Pepira e predominância de declives acentuados à jusante $(>18 \%)$. Nas regiões de alta declividade, a água pluvial tende a escoar superficialmente em direção aos rios e lagos. Por outro lado, em áreas pouco declivosas espalhadas por toda a região de estudo, a água tende a se infiltrar. Do ponto de vista da vulnerabilidade, declives suavizados favorecem a infiltração da água e potenciais contaminantes, sobretudo se o contaminante em questão for um pesticida. Em vista disso, nestas áreas há maior suscetibilidade à presença de compostos não-naturais agressivos ao meio.

A Condutividade Hidráulica é uma propriedade do meio físico que reflete a facilidade ou dificuldade de movimentação da água subterrânea. Formações geológicas com alta condutividade hidráulica permitem a movimentação horizontal e vertical de grandes volumes de água subterrânea, e, por associação, de grandes volumes de contaminantes em potencial. Com base nos valores obtidos a partir de revisão da literatura, na Sub-Bacia Jacaré-Pepira foram encontrados valores de condutividade hidráulica relativamente baixos, que representaram baixa suscetibilidade do meio à contaminação.

A quantificação da vulnerabilidade de aquíferos tem viés preventivo em relação a eventos de contaminação, sejam eles oriundos de fontes pontuais ou difusas na região de estudo mapeada. As diferenças percebidas entre DRASTIC Padrão e DRASTIC Pesticidas ocorreram devido aos diferentes pesos atribuídos por Aller et al. $(1985,1987)$ a cada parâmetro que refletem as diferentes interações entre os contaminantes hipotéticos de cada modelo. Por exemplo, para DRASTIC Padrão, dado que o contaminante tem características próximas à da água, o solo atua como um potencial meio de atenuação do contaminantes. Já para DRASTIC Pesticidas, dado que o contaminante tem características próximas a um pesticida típico, o solo atua como um reservatório de contaminante.

Com isso, a fim de evitar o comprometimento da qualidade dos recursos hídricos subterrâneos, propõe-se a consolidação da geoespacialização da vulnerabilidade das águas subterrâneas como critério técnico-científico mandatório às políticas públicas na regionalização de atividades econômicas, considerando a proibição de atividades potencialmente impactantes em áreas mais vulneráveis. Para locais onde há baixa vulnerabilidade, podem ser alocadas atividades com maior potencial de contaminação, condicionando-as, no entanto, a rotinas de monitoramento rigorosas com vistas à conservação ambiental do meio natural e, por conseguinte, à proteção das águas subterrâneas.

\section{CONCLUSÕES}

O mapeamento da vulnerabilidade a partir do método DRASTIC em suas variações Padrão e Pesticidas permitiu comparar as interações entre diferentes comportamentos de contaminantes no meio físico, sendo um com mobilidade similar à da água (DRASTIC Padrão) e outro referente a alta mobilidade típica dos pesticidas (DRASTIC Pesticidas).

Os resultados obtidos indicam predominância de Vulnerabilidade Baixa a Moderada para o procedimento DRASTIC Padrão, enquanto DRASTIC Pesticidas obteve Vulnerabilidade Moderada a Alta na maior parte da 
área avaliada, diferença essa devido às diferentes mobilidades dos contaminantes considerados nos dois cenários.

A aplicação do método DRASTIC para quantificação da vulnerabilidade de águas subterrâneas mostrou-se uma ferramenta de diagnóstico quantitativa, de baixo custo e de execução consideravelmente rápida a partir de dados secundários. A execução deste mapeamento regional de alta confiabilidade evidencia a viabilidade de identificação de áreas mais suscetíveis à contaminação, podendo orientar decisões futuras acerca do zoneamento industrial em áreas suscetíveis à contaminação.

A análise da distribuição da vulnerabilidade demonstrou a influência de cada parâmetro no resultado final de vulnerabilidade, podendo direcionar futuros estudos locais específicos. Neste estudo, por exemplo, foram

\section{REFERÊNCIAS}

ALBUQUERQUE FILHO, J. L.; CARVALHO, A. M. de; IKEMATSU, P.; BARBOSA, M. C.; IRITANI, M.; PRESSINOTTI, M. M. N., ROCHA, G.; SILVA, M. P. M. da; THEODOROVICZ, A.; Diretrizes para o desenvolvimento e proteção ambiental da área de afloramento do Sistema Aquífero Guarani no estado de São Paulo, Brasil. Boletín Geológico y Minero, v.123, n.3, p. 353-366. 2012.

ALLER, L.; BENNET, T.; LEHER, J.H.; PETTY, R.J. DRASTIC: a standardized system for evaluating ground water pollution potential using hydrogeologic setting. USEPA Report 600/0285/018. Environmental Research Laboratory; Ada, Oklahoma. 1985.

ALLER, L.; BENNET, T.; LEHER, J.H.; PETTY, R.J.; HACKETT, G. DRASTIC: a standardized system for evaluating ground water pollution potential using hydrogeologic setting. USEPA Report 600/02-87/035. Environmental Research Laboratory; Ada, Oklahoma. 1987.

ALMEIDA, O. A. Qualidade da Água de Irrigação. Embrapa Mandioca e Fruticultura, Cruz das Almas, ed.1, 2010.

CHRISTOFIDIS, D.; Água, ética, segurança observadas vulnerabilidades maiores em áreas com menores profundidades do nível d'água, enquanto que os valores de índice vulnerabilidade do parâmetro C (Condutividade Hidráulica) não tiveram variação espacial. Portanto, estudos em escalas locais podem evidenciar variações nos índices dos parâmetros não detectadas em estudo regionais e permitir uma estimativa da vulnerabilidade mais precisa.

Adicionalmente, ainda que o mapeamento regional resultante do método DRASTIC seja consultado previamente à instalação de novos empreendimentos, recomenda-se a execução de novos estudos afim de melhorar o diagnóstico da fragilidade do meio frente a contaminantes específicos, considerando as diferentes interações do contaminantes com o meio natural.

alimentar e sustentabilidade ambiental. Bahia: Análise \& Dados Salvador, v. 13, n. especial, p. 371-382, 2003.

COMPANHIA AMBIENTAL DO ESTADO DE SÃO PAULO - CETESB. [Site]. Proteção da Qualidade das Águas Subterrâneas. Disponível em: <http://www.cetesb.sp.gov.br/agua/Informa??es-B?sicas/3-Polui??o-das-?guas-Subterr?neas>. Acesso em 25 de abril de 2014a.

COMPANHIA AMBIENTAL DO ESTADO DE SÃO PAULO - CETESB. [Site]. A Poluição das Águas Subterrâneas. Disponível em:http://www.cetesb.sp.gov.br/agua/Informa??es-B?sicas/3-Polui??o-das-?guas-Subterr?neas. Acesso em 25 de abril de 2014b.

COELHO, V. H. R.; MONTENEGRO, S. M. G.; ALMEIDA, C. das N.; LIMA, E. R. V. de; NETO, A. R.; MOURA, G. S. S. de; Dinâmica do uso e ocupação do solo em uma bacia hidrográfica do semiárido brasileiro. R. Bras. Eng. Agríc. Ambiental, v.18, n.1, p.64-72, 2013.

CPRM (Serviço Geológico do Brasil). Geodiversidade do Estado de São Paulo. Programa Geologia do Brasil - Levantamento da Geodiversidade. 2010 . 
ERTEL T.; LÖBLER, C. A.; SILVA, J. L. S. da; Índice de vulnerabilidade das águas subterrâneas no município de Rosário do Sul, Rio Grande do Sul. Revista Eletrônica em Gestão, Educação e Tecnologia Ambiental, v. 7, n. 7, p. 1400-1408. 2012.

FERRARO, A. A.; GABAS, S. G.; LASTORIA, G. Origem de Metais Pesados em Aquífero Livre de São Gabriel do Oeste, Mato Grosso do Sul. São Paulo, UNESP, Geociências, v. 34, n. 4, p.801815. 2015.

FIJANI, E. NADIRI A. A.; MOGHADDAM A.A.; TSAI F. T. C.; DIXON B. Optimization of DRASTIC method by supervised committee machine artificial intelligence to assess groundwater vulnerability for Maragheh-Bonab plain aquifer, Iran. Journal of Hydrology, p. 89-100. 2013.

HIRATA, R. C. A.; Fundamentos e estratégias de proteção e controle da qualidade das águas subterrâneas. Estudo de casos no estado de São Paulo. Universidade de São Paulo (USP). 1994. IPT (Instituto de Pesquisas Tecnológicas do Estado de São Paulo). Mapa Geológico do Estado de São Paulo. Escala 1:500.000. São Paulo: IPT, volume 2. 124 p. (Monografias, 6; Publicação, 1 184). 1981.

JESUS, I. P. S. de; Caracterização dos aquíferos em meio cristalino na porção oeste da Bacia do Alto Tietê. Tese (Doutorado). Instituto de Geociências, Universidade de São Paulo (USP), São Paulo. 2012.

KÖPPEN, W. Climatologia: con un estudio de los climas de la tierra. México: Fundo de Cultura Econômica. 474 p. 1948.

LNEC (Laboratório Nacional de Engenharia Civil). Cartografia da Vulnerabilidade à poluição das águas subterrâneas do concelho de Montemor-o-Novo utilizando o método DRASTIC. LNEC, Departamento de Hidráulica, Grupo de Investigação de Águas Subterrâneas, Lisboa, Proc.607/1/14252. 2002.

LAGO, W. N. M.; LACERDA, M. P. C.; NEUMANN, M. R. B.; BORGES, T. D. Ocupação e adequação do uso das terras na microbacia do Ribeirão Extrema, Distrito Federal - Parte I. Revista Brasileira de Engenharia Agrícola e Ambiental, v.16, p.289- 296. 2012.
LEITE, C.B.B.; HENRIQUES, M. J. A. N.; TOPOROVSKI C.Z.; LOBO FERREIRA J. P. Avaliação da Vulnerabilidade à Contaminação das Águas Subterrâneas na Bacia Hidrográfica Tietê/Jacaré - UGRHI-13. Simpósio de Hidráulica e Recursos Hídricos dos Países de Língua Oficial Portuguesa (SILUSBA). 2011.

LEITE, C. B.B. ; ALBUQUERQUE FILHO, J. L.; SILVA, E. V. E.; Avaliação e Quantificação do Parâmetro Recarga de Águas Subterrâneas na Bacia Hidrográfica Tietê/Jacaré - UGRHI 13. Instituto de Pesquisas Tecnológicas - IPT. Relatório Final. 2013.

LIBOS, M. I. P. de C. Modelagem da Poluição não Pontual na Bacia do Rio Cuiabá. (Doutorado), Universidade Federal do Rio de Janeiro, COPPE/UFRJ. 2002.

LIMA, E. B. N. R. Modelagem Integrada para Gestão da Qualidade da Água na Bacia do Rio Cuiabá. Tese (Doutorado em Engenharia Civil), Universidade Federal do Rio de Janeiro, COPPE/UFRJ. Rio de Janeiro, RJ. 2001.

LOBO-FERREIRA, J.P.C. Vulnerabilidade à poluição de águas subterrâneas: fundamentos e conceitos para uma melhor gestão e protecção dos aquíferos de Portugal. $4^{\circ}$ Congresso da Água, Lisboa. 1998.

MACHADO, R. E. Simulação de Escoamento e de Produção de Sedimentos em uma Microbacia Hidrográfica Utilizando Técnicas de Modelagem e Geoprocessamento - Piracicaba-SP. 154 p. Tese (Doutorado), Escola Superior de Agricultura Luis de Queiros. 2002.

MARENGO, J. A. Hydro-climatic: and ecological behaviour of the drought of Amazonia in 2005. Philosophical Transactions of the Royal Society of London. Biological Sciences, v.21, p.1-6. 2008.

MCGUFF, H. e MCMULLEN, A. Exploring Aquifer Vulnerability for Hornby Island BC. In: GIS 470 Term Project, University of British Columbia. Canadá. 2004.

MENEZES, J. P. C.; BERTOSSI, A. P. A.; SANTOS A. R. dos; NEVES M. A. Qualidade da água subterrânea para consumo humano e uso agrícola no sul do estado do Espírito Santo. 2013. 
MIRANDA, C. S.; MIOTO, C. L.; LASTORIA G.; GABAS, S. G.; PARANHOS FILHO, A. C.; Uso de Sistemas de Informação Geográfica (Sig) na Modelagem da Vulnerabilidade de Aquífero Livre: Comparação entre os Métodos God e Ekv na Bacia do Rio Coxim, São Gabriel do Oeste, MS, Brasil. São Paulo, UNESP, Geociências, v. 34, n. 2, p.312-322. 2015

MUHAMMAD A.M., ZHONGHUA, T., DAWOOD A. S., EARL B. Evaluation of local groundwater vulnerability based on DRASTIC index method in Lahore, Pakistan. International Geophysics, 2014.

OLIVEIRA, M. M. Recarga de águas subterrâneas: Métodos de avaliação. Tese (Doutorado). Universidade de Lisboa, Faculdade de Ciências, Departamento de Geologia, 440 p. 2004.

PRADO, H. do; OLIVEIRA, J. B. de; ALMEIDA, C. L. F. de. Levantamento Pedológico SemiDetalhado no Estado de São Paulo. Quadrícula de São Carlos. SF.23-Y-A-I. Escala 1:100.000. Convênio EMBRAPA (Empresa Brasileira de Pesquisa Agropecuária) - IAC (Instituto Agronômico de Campinas). 1981.

SANTOS, R. G.; STURARO, J. R.; MARQUES, M. L.; FARIA, T. T. GIS Applied to the Mapping of Land Use, Land Cover and Vulnerability in the Outcrop Zone of the Guarani Aquifer System. Procedia Earth and Planetary Science, 15, p. $553-559,2015$.

SÃO PAULO. Plano Estadual de Recursos Hídricos - Conselho Estadual de Recursos
Hídricos - CRH/CORHI - GTP. São Paulo, 137 p., 1990.

SHRESTHA, S.; SEMKUYU, D.J.; PANDEY, V. P. Assessment of groundwater vulnerability and risk to pollution in Kathmandu Valley, Nepal. Science of the Total Environment, 556, p. 2335. 2016.

SiBICS - Sistema Brasileiro de Classificação de Solos. Brasília/DF - Brasil. $2^{\mathrm{a}}$ ed., 286 p. 2006.

SPERLING, E. V. Princípios do tratamento biológico de águas residuais. Ed. 3, v.1. Belo Horizonte: Departamento de Engenharia Sanitária e Ambiental, 452 p. 2005.

TUCCI, C. E. M.; HESPANHOL, I.; NETTO, O. de M., C. Cenários da Gestão da Água no Brasil: Uma Contribuição para a Visão Mundial da Água. Revista Brasileira de Recursos Hídricos, v. 5, n. 3, 31-43. 2000.

TUNDISI, J. G.; TUNDISI, T. M.; PARESCHI, D, C.; LUZIA, A. P.; HAELING P. H. VON.; FROLLINI, E. H. A bacia hidrográfica do Tietê/Jacaré: estudo de caso em pesquisa e gerenciamento. Revista Estudos Avançados. 2008.

VRBA J.; ZAPOROZEC A. Guidebook on mapping groundwater vulnerability, vol 16. In: International contributions to hydrogeology, Heise, Hannover, Germany, 131 p. 1994.

YOUNOS,T. M.; WEIGMANN, D. L. Pesticides a Continuing Dilemma. J water pollut control fed, 60, p. 1199-1205. 1988. 